Journal of Development and Social Change, Vol. 2, No. 1, April 2019

p-ISSN 2614-5766, https://jurnal.uns.ac.id/jodasc

\title{
KONFLIK SOSIAL ANTARA OJEK PANGKALAN DAN GOJEK DI KOTA SURAKARTA
}

\author{
Dwi Nurindah Rahayu ${ }^{1}$, Ahmad Zuber ${ }^{2}$ \\ Program Studi Sosiologi Fakultas Ilmu Sosial dan Politik \\ Universitas Sebelas Maret Surakarta Indonesia \\ Email $^{1}$ : Dwi.nurindah23@gmail.com,Email²: a.zuber@staff.uns.ac.id
}

\begin{abstract}
In this research try to raise the theme of conflict research between traditional ojek drivers and GoJek in the city of Surakarta. GoJek is present with various services needed and influential for the community in all activities quickly and efficiently. But on the other hand Gojek is a rival for traditional ojek drivers and the exsistence of GoJek triggers conflict. The purpose of this research is to find out how conflicts occur between traditional ojek drivers and GoJek, what are the forms of conflict, factors that affect conflict and how conflict prevention efforts. The theory used is social conflict theory from Lewis L. Coser. Types of research used in this phenomenon is descriptive qualitative, with data collection techniques through observation, interviews and from secondary data and documentation. The sample uses a purposive sampling technique. With the stipulation of the informants of the traditional ojek drivers, GoJek drivers and traditional ojek and GoJek consumers. The data validity technique uses source triangulation. While the data analysis uses 3 channels namely data reduction, data presentation and drawing conclusions.

The results showed that the conflict that occurred between traditional ojek driver and GoJek occurred due to the reduced income of ojek, because people preferred to use GoJek. The form of conflict that occurs between conventional ojek and GoJek is divided into two, namely the form of manifest conflict (open) and latent conflict (closed). Forms of manifest conflicts include beatings, quarrels and struggles for attributes. While latent forms of conflict include jealousy and envy and disappointment. Conflict between conventional ojek and GoJek is caused by several factors including land limitations, system differences, and tariff differences. So that the conflict does not continue, several efforts have been made to overcome the conflict, namely the determination of the red zone boundary, warning or warning, and reporting to the authorities.
\end{abstract}

Keywords: Base ojek, Conflict, GoJek,

Abstrak: Dalam penelitian ini mencoba mengangkat tema penelitian konflik antara pengemudi ojek pangkalan dan GoJek di Kota Surakarta.GoJek hadir dengan berbagai layanan yang dibutuhkan dan berpengaruh bagi masyarakat dalam segala aktifitas secara cepat dan efisien. Namun disisi lain Gojek merupakan suatu saingan bagi ojek pangkalan dan keberadaan GoJek memicu adanya konflik. Tujuan penelitian adalah untuk mengetahui bagaimana konflik yang terjadi antara ojek pangkalan dan GoJek, apa saja bentuk-bentuk konflik, faktor yang mempengaruhi konflik dan bagaimana upaya penanggulangan konflik.Teori yang digunakan yakni teori konflik sosial dari Lewis L. Coser.Jenis penelitian yang digunakan dalam fenomena ini adalah deskriptif kualitatif, dengan teknik pengumpulan data lewat observasi, wawancara dan dari data sekunder serta dokumentasi. Sampel menggunakan teknik purposive sampling. Dengan ketetapan informan pengemudi ojek pangkalan, pengemudi GoJek dan konsumen ojek dan GoJek. Teknik validitas data menggunakan triangulasi sumber.Sedangkan analisa data menggunakan 3 alur yakni reduksi data, sajian data dan penarikan simpulan. 
Hasil penelitian menunjukkan bahwa konflik yang terjadi antara ojek pangkalan dan GoJek terjadi karena berkurangnya pendapatan ojek pangkalan, karena masyarakat lebih memilih menggunakan GoJek. Bentuk konflik yang terjadi antara ojek pangkalan dan GoJek terbagi menjadi dua, yaitu bentuk konflik manifes (terbuka) dan konflik laten (tertutup). Bentuk konflik manifes antara lain pengeroyokan,adu mulut dan perebutan atribut. Sedangkan bentuk konflik laten antara lain iri dan dengki serta kecewa. Konflik yang terjadi antara ojek pangkalan dan GoJek di sebabkan oleh beberapa faktor diantaranya keterbatasan lahan, perbedaan sistem, dan perbedaan tarif. Agar konflik tidak terus berkelanjutan maka terbetuk beberapa upaya untuk menanggulangi konflik yaitu penetapapan batas zona merah, teguran atau peringatan, dan melaporkan keapada pihak yang berwenang.

Kata kunci : Ojek pangkalan, GoJek, Konflik

\section{PENDAHULUAN}

Transportasi didefinisikan sebagai suatu sistem yang terdiri dari fasilitas tertentu beserta arus dan sistem control yang memungkinkan orang atau barang dapat berpindah dari suatu tempat ke tempat lain secara efisien dalam setiap waktu untuk mendukung aktivitas manusia ( Papacostas, 1987). Transportasi merupakan komponen utama dalam sistem hidup dan kehidupan, sistem pemerintahan, dan sistem kemasyarakatan. Kondisi sosial demografis wilayah memiliki pengaruh terhadap kinerja transportasi di wilayah tersebut. Tingkat kepadatan penduduk akan memiliki pengaruh signifikan terhadap kemampuan transportasi melayani kebutuhan masyarakat.

Memasuki era global teknologi berkembang pesat. Salah satu hasil kemajuan teknologi informasi yang berkontribusi besar terhadap perubahan ini adalah internet. Perkembangan teknologi salah satunya internet juga diikuti meningkatnya jumlah pengguna internet di setiap negara, salah satunya Indonesia. Menurut data survey APJII ( Asosiasi Penyelenggara Jasa Internet Indonesia), yang dirilis pada 20 Februari 2018, populasi netter tanah air mencapai 72,8 juta orang pada tahun 2013. Angka pengguna Internet di Indonesia tahun 2014 sebanyak 88.1 juta. Setiap bulan angka setiap orang yang mengakses internet semakin bertambah. Pengguna internet di Indonesia pada 2017 telah mencapai 143,3 juta jiwa dengan penetrasi sebesar 54,69 persen dari total populasi (APJII, 2018).

Internet tidak hanya berfungsi sebagai alat komunikasi seperti mengirim surat elektronik atau email saja seperti pada awal perkembangannya. Akan tetapi juga sudah merambah kepada interaksi yang lebih kompleks lagi. Seperti dalam beberapa tahun ini banyak sekali bermunculan aplikasi layanan jasa yang beragam dan bervariasi salah satunya dalam bidang jasa transportasi.

Kehadiran jasa transportasi berbasis aplikasi online yang menggunakan internet sangat berpengaruh bagi masyarakat dalam segala aktifitas secara cepat dan efisien. Salah satu bisnis yang sedang berkembang saat ini adalah bisnis jasa transportasi dengan sepeda motor atau yang dulu biasa disebut ojek. Ojek dahulu dikelola secara konvensional namun dengan adanya perkembangan internet muncul inovasi baru yaitu ojek yang menggunakan aplikasi online, menjadi ojek online.

Salah satu ojek berbasis aplikasi online di Indonesia adalah GoJek. GoJek lahir dari ide sang CEO dan Managing Director Nadiem Makarim yang mengaku seorang pengguna ojek. Dengan pengalamannya saat naik ojek di jalanan yang macet inilah ia kemudian menciptakan GoJek, sebuah layanan antar jemput dengan ojek modern berbasis pesanan. Gojek dapat di pesan melalui GoJek app yang bisa diunduh melalui play store maupun app store (Go-Jek, 2017). 
GoJek diluncurkan di Kota Surakarta pada tanggal 25 Mei 2016. Meski sudah diluncurkan, sejauh ini hanya tiga layanan yang sering diakses pengguna jasa Go-Jek di Surakarta, yaitu Go-Ride (layanan transportasi roda dua), Go-Send (layanan kurir atau pengiriman barang), dan Go-Food (layanan delivery makanan).

Sejak munculnya GoJek di Kota Surakarta menimbulkan persaingan antara Gojek dan Ojek Pangkalan. Persaingan yang terjadi diantara Gojek dan Ojek pangkalan ini lambat laun menimbulkan konflik. Konflik yang terjadi karena Ojek Pangkalan merasa jika pekerjaanya diambil alih oleh Gojek. Mereka merasa kehilangan penumpang ketika hadirnya Gojek. Para ojek pangkalan merasa tersaingi dengan kehadiran Gojek.

Persaingan yang terjadi diantara Gojek dan ojek pangkalan ini lambat laun menimbulkan konflik. Konflik yang terjadi karena ojek pangkalan merasa jika pekerjaanya diambil alih oleh Gojek. Mereka merasa kehilangan penumpang ketika hadirnya Gojek. Para ojek pangkalan merasa tersaingi dengan kehadiran Gojek ini. Hal ini sesuai dengan yang diungkapkan oleh Setiadi dan Kolip (2011, hlm. 361) bahwa penyebab konflik yaitu : Perbedaan antar individu diantaranya perbedaan pendapat, tujuan, keinginan, pendirian tentang objek yang dipertentangkan. Di dalam realitas sosial tidak ada satupun individu yang memiliki karakter yang sama sehingga perbedaan karakter itulah yang mempengaruhi timbunya konflik sosial.

Menurut masyarakat kehadiran Gojek dianggap sebagai salah satu bentuk kemudahan dalam menggunakan layanan jasa secara praktis. Masyarakat Surakarta yang juga terdapat banyak mahasiswa mengaku sangat terbantu dengan adanya jasa GoJek, selain mudah GoJek juga dinilai lebih murah daripada ojek pangkalan, terlebih lagi jasa layanan GoJek dilengkapi dengan berbagai fasilitas unggulan yang memberikan nilai lebih bagi para konsumen atau pengguna layanan tersebut, namun pemerintah Kota Surakarta sendiri belum yakin akan adanya inovasi ojek online tersebut, karena Kota Surakarta diangap kota yang kecil dan belum membutuhkan inovasi ojek online tersebut, pemerintah Kota Surakarta ingin Surakarta tetap menjadi simbol kota yang tradisional dengan tetap mempertahankan becak kayuh dan ojek pangkalan sebagai transportasi di Kota Surakarta. Penelitian ini mempunyai tujuan untuk mengetahui bagaimana konflik antara ojek pangakalan dan GoJek di Kota Surakarta, apa saja faktor yang menyebabkan konflik dan bagaimana upaya untuk menanggulangi konflik tersebut.

\section{METODE PENELITIAN}

Penelitian ini merupakan penelitian kualitatif dengan jenis pendekatan deskripsi kualitatif. Penelitian ini dilakukan di Kota Surakarta dimana peneliti menemukan konflik ini. teknik pengambilan informan dilakukan dengan menggunakan teknik purposive sampling. Peneliti mengambil 11 informan berdasarkan kriteria yang sudah ditentukan. Informan tersebut adalah pengemudi GoJek dan pengemudi ojek pangkalan, pihak penengah konflik yaitu oihak Kepolisian Kota Surakarta, serta masyarakat yang menggunakan jasa ojek pangkalan dan GoJek.

Sumber data dalam penelitian ini diperoleh melalui observasi, wawanncara dan dokumentasi dengan informan yang telah ditetapkan dan diperoleh melalui proses wawancara. Adapun validitas data dalam penelitian ini menggunakan triangulasi data (sumber) yaitu pengumpulan data menggunakan beberapa sumber data untuk mengumpulkan data yang sama, serta triangulasi metedologis dimulai dengan survey dan observasi lokasi penelitian serta wawancara narsumber. Analisa melalui tiga alur kegiatan yaitu reduksi data, penyajian data, dan penarikan kesimpulan. 


\section{HASIL DAN PEMBAHASAN}

\section{Konflik Antara Ojek Pangkalan dan GoJek}

GoJek belum mengantongi izin resmi dari pemerintah Kota Surakarta. Sejak beroperasi tahun 2016 GoJek belum mengantongi ijin dari pemerintah Kota Surakarta. Hal ini dikarenakan aturan yang menjelaskan bahwa sepeda motor bukan termasuk transportasi untuk mengangkut penumpang. Hal tersebut diungkapkan langsung oleh walikota Surakarta pada acara audensi bertempat di Balai Kota Surakarta hari Rabu tanggal 25 Januari 2017 pukul 08.30 WIB s/d 11.15 WIB bertempat di pendhopo Gedhe Balaikota Surakarta J1 Jend. Sudirman No. 2, berkumpul ratusan tukang ojek pangkalan, Forum Komunikasi Keluarga Becak (FKKB), dan GoJek.

Ojek pangkalan merupakan salah satu mata pencaharian bagi beberapa masayarakat di Kota Solo, menjadi tukang ojek pangkalan saat itu hanya bermodalkan motor dan bensin lalu menunggu di pangkalan untuk mendapatkan penumpang. Penghasilan yang diperoleh dari menjadi tukang ojek pangkalan dahulu cukup untuk memenuhi kebutuhan sehari-hari karena masayarakat memang masih banyak yang menggunakan jasa ojek pangkalan. Namun sejak kemunculan Gojek dan mulai menyebar di Kota Solo, penghasilan tukang ojek pangkalan menurun dratis. Jumlah penumpang yang menurun drastis membuat penghasilan tukang ojek pangkalan pun menurun hal tersebut yang membuat tukang ojek pangkalan berlomba-lomba mendapatkan penumpang dengan GoJek, beberapa cara dilakukan oleh ojek pangkalan untuk mendapatkan penumpang, seperti masuk ke stasiun atau terminal dengan menawarkan jasa ojek secara langsung atau dengan mencari penumpang diluar dari pangkalan. Hal tersebut dilakukan agar cepat mendapatkan penumpang.

Selain pendapatan yang menurun yang dirasakan oleh para pengemudi ojek pangkalan adalah masalah kenyamanan. Suasana sekarang tidak senyaman dulu saat belum ada GoJek, sejak ada Gojek menjadi sering terjadi konflik khususnya masalah penumpang. Munculnya GoJek membuat pengemudi ojek pangkalan khawatir karena merasa tersaingi dalam mencari penumpang, belum lagi tukang ojek pangkalan kini merasa resah karena banyak GoJek mengambil penumpang di wilayahnya, sehingga jarang ada lagi masyarakat yang menggunakan jasa ojek pangkalan. Kondisi tidak nyaman juga dirasakan karena sejak kemunculan GoJek sering terjadi konflik antara ojek pangkalan dan GoJek, tidak aman dan nyaman lagi seperti dahulu sebelum ada GoJek.

\section{Bentuk-bentuk Konflik Antara Ojek Pangkalan dan GoJek}

a. Konflik Manifes

Konflik manifes merupakan suatu bentuk permasalahan sosial (baik dalam bentuk perselisihan hingga konflik) yang tampak di permukaan sosial atau masyarakat, diketahui oleh orang banyak dan pengakuan terbuka antara dua pihak atau lebih yang sedang bermasalah.

1) Pengeroyokan

Pengeroyokkan merupakan salah satu bentuk konflik fisik yang sering terjadi di masyarakat. Pengeroyokan terjadi antara dua kubu atau lebih dan melibatkan beberapa pihak. Tindak pengeroyokan merupakan konflik yang cukup berat karena menggunakan kekerasan fisik, dan menimbulkan jatuhnya korban. Konflik berupa pengeroyokan antara GoJek dan Ojek pangkalan terjadi saat awal GoJek beroperasi di Kota Surakarta. tindak pengeroyokan dilakukan oleh kubu tukang ojek pangkalan terhadap GoJek karena tidak terima akan kehadiran GoJek yang mengakibatkan penghasilan ojek pangkalan menurun, dan menambah saingan dalam bekerja. Salah satu kasus pengeroyokan tukang 
ojek pangkalan terhadap GoJek terjadi pada tahun 2016, kejadian pengeroyokan tersebut terjadi di kawasan Stasiun Purwosari Kota Solo. Seorang pengemudi GoJek di Solo dikeroyok sekelompok orang tak dikenal. Sebelumnya pengemudi GoJek tersebut menerima pesan dari seorang yang memesan untuk diantar. Namun saat berada di lokasi yang disebutkan pemesan, pengemudi itu justru didatangi sekelompok orang yang langsung menyerangnya.

2) Adu Mulut

Adu mulut merupakan salah satu konflik yang sering terjadi dalam masyarakat. Adu mulut sering terjadi karena perasaan tidak suka atau kesalah pahaman antara dua pihak atau lebih. Adu mulut terkadang tidak menggunakan fisik hanya saling melempar kata-kata atau umpatan yang tidak baik. Adu mulut sering terjadi antara tukang ojek pangkalan dengan GoJek. Hal yang menyebabkan adu mulut antara tukang ojek pangakalan dan GoJek adalah GoJek sering melanggar peraturan yang telah di sepakati bersama antara GoJek dan tukang ojek pangkalan. Salah satu contohnya adalah GoJek melanggar zona merah. Tindakan yang dilakukan saat ada Gojek yang melanggar yaitu pengemudi ojek pangkalan mendatangi pengemudi Gojek, merasa kesal dengan pengemudi GoJek, terjadilah cek cok atau adu mulut antara Gojek dan pengemudi ojek pangkalan.

3) Perebutan Atribut

Hal yang dilakukan oleh tukang ojek pangkalan terhadap GoJek yang melanggar aturan selain konflik fisik dan adu mulut adalah perebutan atribut. Atribut GoJek yang diambil oleh tukang ojek pangkalan adalah jaket atau helm yang merupakan fasilitas yang diberikan oleh kantor GoJek, hal tersebut dilakukang kepada pengemudi Gojek yang sering melanggar peraturan zona merah. Tujuan perebutan atribut adalah untuk memberi efek jera bagi pengemudi GoJek yang melanggar peraturan, khususnya peraturan mengenai zona merah atau batas penjemputan di stasiun atau terminal. Perebutan atribut dilakukan sebagai tindakan tegas untuk GoJek yang melanggar aturan.

\section{b. Konflik Laten}

Konflik laten merupakan suatu bentuk permasalahan sosial (baik dalam bentuk perselisihan hingga konflik) yang tidak tampak di permukaan sosial / masyarakat, tidak banyak diketahui orang, sifatnya diam-diam dan tidak terjadi pengakuan terbuka antara dua pihak atau lebih yang sedang bermasalah.

1) Iri dan dengki

Iri dan dengki disini dialami oleh tukang ojek pangkalan terhadap pengemudi GoJek di Surakarta. Perasaan iri dan dengki yang dirasakan oleh tukang ojek pangkalan terjadi karena masyarakat lebih memilih menggunakan jasa GoJek daripada menggunakan ojek pangkalan. Para tukang ojek pangkalan merasa iri karena pendapatan yang diperoleh tidak sama dengan pengemudi GoJek, padahal para pengemudi ojek pangkalan sudah menunggu penumpang di pangkalan dalam waktu yang lama.

2) Kecewa

Perasaan kecewa dirasakan oleh beberapa pengemudi ojek pangkalan di Kota Surakarta terhadap pemerintah Kota Surakarta karena tidak ada kejelasan 
tentang ijin operasi GoJek di Kota Surakarta, namun sudah banyak GoJek yang diperbolehkan beroperasi. Karena hal tersebut pengemudi ojek pangkalan dan pengayuh becak di Solo menggelar aksi penolakan terhadap GoJek dengan mendatangi balai kota untuk mendesak pemerintah kota (pemkot) untuk menindak pengemudi Gojek yang beroperasi tanpa ijin di Kota Surakarta.

\section{Faktor Penyebab Konflik}

a. Keterbatasan Lahan

Keterbatasan lahan yang dimaksud dalam penelitian ini adalah keterbatasan lahan yang dimiliki oleh ojek pangkalan, ojek pangkalan terbagi atas beberapa paguyuban yang tersebar seperti di Stasiun Solo Balapan, Stasiun Purwosari, Terminal Tirtonadi dan depan Kampus UNS Solo.Dalam setiap paguyuban hanya boleh mengangkut penumpang di wilayah tersebut, tidak boleh mengambil penumpang di paguyuban lain atau di wilayah lain, hal tersebut membuat lahan untuk mencari penumpang sangat sempit.Berbeda dengan GoJek yang dapat mengangkut penumpang dimana saja, termasuk di stasiun atau terminal

b. Perbedaan Sistem

Perbedaan sistem merupakan salah satu faktor terjadinya konflik antara ojek pangkalan dan GoJek, dalam hal ini adalah perbedaan sistem untuk mendapatkan penumpang. Ojek Pangkalan masih kurang canggih, karena masih menggunakan sitem menunggu penumpang di pangkalan, jadi penumpang yang mencari tukang ojek. Berbeda dengan GoJek yang menggunakan aplikasi untuk mencari penumpang, di era digital ini tidak dipungkiri bahwa banyak aplikasi yang berguna dan mempermudah pekerjaan masayarakat, salah satunya aplikasi GoJek masyarakat sebagian besar sudah mengunduh aplikasi GoJek. Masyarakat hanya perlu memesan GoJek melalui aplikasi lalu GoJek datang untuk menjemput sesuai lokasi yang sudah ditentukan oleh penumpang.

c. Perbedaan Tarif

Tarif menjadi salah satu faktor penyebab konflik, karena ojek pangkalan merasa bahwa tarif GoJek lebih murah dibandingkan ojek pangkalan untuk tujuan yang sama. Tarif GoJek ditentukan dari kantor GoJek, dengan tariff minimal Rp.8000, berbeda dengan tariff ojek pangkalan yang ditentukan langsung oleh pengemudi ojek dan sesuai kesepakatan dengan penumpang. Perbedaan tariff inilah yang membuat masyarakat beralih menggunakan GoJek hal ini yang mengakibatkan kesenjangan sosial diantara GoJek dan Ojek pangkalan.

\section{Upaya Penanggulangan Konflik}

a. Penetapan Zona Merah

Konflik terjadi saat pengemudi Gojek mengambil penumpang di kawasan pengemudi ojek pangkalan, sperti terminal, stasiun dan beberapa titik lainnya, untuk itu pihak GoJek membuat batas-batas untuk pengambilan penumpang oleh Gojek yang disebut dengan zona merah, hal tersebut sudah sesuai dengan kesepakatan anatara menejemen GoJek dan setiap ojek pangkalan, Batas zona merah dibuat oleh pihak Gojek dan disepakati oleh pihak ojek pangkalan sebagai batas yang diperbolehkan Gojek mengambil penumpang. Batas tersebut terdapat di stasiun dan terminal, jarak yang diberikan sekita 200 meter dari stasiun dan terminal, sehingga penumpang yang ingkin menggunakan Gojek harus berjalan kaki sejauh 200 meter sesuai lokasi Gojek berada. 
b. Memberi Teguran atau peringatan

Batas zona merah yang telah ditetapkan oleh pihak Gojek dan pihak ojek pangkalan seharusnya di taati agar tidak terjadi konflik lagi, namun hingga saat ini masih ada beberapa oknum GoJek yang melanggar batas zona merah tersebut, sehingga memicu konfilk dengan pengemudi ojek. Tindakan pertama untuk penyelesaian konflik yang dilakukan pengemudi ojek pangkalan terhadap GoJek yang melanggar zona merah adalah memberi teguran atau peringatan. Peringatan yang diberikan kepada Gojek yang melanggar aturan zona merah berupa teguran agar tidak melakukan hal tersebut lagi, dan sebagai peringatan agar memberi tahu sesama GoJek agar lebih berhati-hati. Penyelesaian konflik dilakukan pembicaraan baikbaik dengan memberi teguran dan peringatan untuk tidak melakukan pelanggaran lagi.

c. Melaporkan pihak yang berwajib

Pihak ojek pangkalan akan menindak tegas para pengemudi GoJek yang sering melanggar peraturan dan melakukan kecurangan dalam mengambil peumpang, salah satu tindak tegas pengemudi ojek pangkalan adalah melaporkan pengemudi GoJek yang bermasalah kepada kantor Gojek, agar mendapatkan sanksi dari kantor GoJek.

Dalam upaya penanggulangan konflik antara GoJek dan ojek pangkalan pihak Gojek sudah mempersiapkakan pihak keamanan untuk berjaga-jaga saat konflik terjadi. Upaya penanggulangan konflik juga ditangani langsung oleh Polresta Kota Surakarta sebagai pihak ketiga dan penengah. Konflik yang berujung pada pegeroyokkan tentu sudah menjadi tanggung jawab kepolisian untuk menyelesaikan konflik tersebut agar tercipta kedamaian. Pihak Kepolisian harus mampu mengantisipasi secara dini dalam membentengi masyarakat dan segala kemungkinan yang bakal mengganggu ketentraman masyarakat, polisi bertugas mendamaikan konflik yang tengah berlangsung.

\section{KESIMPULAN}

Ojek pangkalan di Kota Surakarta sama seperti ojek pangkalan pada umumnya. Ojek pangkalan di Surakarta beroperasi sudah lama. Ojek pangakalan berarti para pengemudi ojek yang biasa berkumpul atau menetap (mangkal) di jalan yang sekiranya banyak mendapat penumpang. Biasanya ojek pangkalan bertempat di depan stasiun Balapan Solo, Stasiun Purwosari, Terminal Tirtonadi, dan di depan Kampus UNS. Ojek pangkalan hanya menunggu penumpang di pangkalan, atau masuk ke pintu keluar stasiun untuk mencari penumpang dengan menawarkan jasa ojek.

GoJek menjadi salah satu terobosan bisnis online yang kini sedang digandrungi oleh masyarakat Indonesia saat ini. Gojek merupakan layanan jasa berbasis online yang menawarkan jasa Ojek dengan media aplikasi mobile yang harus di unduh terlebih dahulu di handphone berbasis android dan iOS (iphone). GoJek hadir di Kota Surakarta pada tahun 2016. Pada awal beroperasi Gojek di Kota Surakarta sering terjadi konflik penolakan Gojek khususnya para pengemudi ojek pangkalan, angkutan umum dan becak, karena merasa tersaingi dan mengalami penurunan penumpang dan penghasilan. Demo penolakan Gojek di Balai Kota Surakarta, menuntut ijin beroperasi Gojek dan menghasilkan batas-batas pengambilan penumpang.

Sampai saat ini Gojek masih beroperasi di Kota Surakarta karena masih banyak masyarakat yang membutuhkan jasa Gojek. Berbeda dengan ojek pangkalan yang mana 
penumpang harus mencari pengemudi ojek di pangkalan ojek. Menggunakan Gojek hanya perlu memesan lewat aplikasi Gojek dan menunggu pengemudi datang sesuai lokasi yang sudah di tentukan. Tidak hanya sebagai jasa antar ojek, Gojek juga menyediakan jasa layanan Go-Food, Go-Car, Go-Deals, Go-Bluebird dan masih banyak layanan Gojek yang dapat digunakan masyarakat.

Konflik antara ojek pangkalan dan GoJek di Kota Surakarta terbagi dalam Bentukbentuk Konflik Manifes dan Laten.Menurut hasil penelitian melalaui wawancara mendalam, observasi memaparkan bentuk bentuk konflik yang terjadi antara ojek pangkalan dan Gojek terbagi menjadi dua, yaitu bentuk konflik Manifes (terbuka) dan Konflik Laten (tertutup). Bentuk Konflik Manifes antara lain pengeroyokan,adu mulut dan perebutan atribut. Sedangkan bentuk konflik laten antara lain iri dan dengki serta kecewa. Kemudian dapat disimpulkan juga bahwa konflik antara ojek pangkalan dan Gojek ini merupakan konflik horizontal dimana konflik ini terjadi di kalangan masyarakat sendiri di Kota Surakarta. Konflik ini juga tergolong konflik yang besar karena melibatkan banyak orang di dalamnya.

Terdapat beberapa faktor yang mempengaruhi terjadinya konflik. Berikut faktor penyebab konflik antara Ojek pangkalan dan Gojek yaitu : Keterbatasan lahan, perbedaaan sistem, perebutan penumpang dan penghasilan serta perbedaan tariff. Konflik yang terjadi antara Ojek pangkalan dan Gojek dapat diselesaikan atau di hindari dengan penanggulangan dengan beberapa cara yaitu : Penetapan batas zona merah, memberi teguran atau peringatan, dan melaporkan kepada pihak yang berwenang.

\section{DAFTAR PUSTAKA}

Asosiasi penyelenggara jasa internet indonesia. 2018. Survei tentang penetrasi dan perilaku pengguna internet indonesia.

Denys Lombard, Nusa Jawa; Silang Budaya Batas-Batas Pembaratan jilid 1, (Jakarta: Gramedia Pustaka Utama, 2008), hlm. 134.

Dwi Ratna Nurhajarini, "Trem Di Surabaya Masa Kolonial Sampai Pasca Kolonial”, dalam Patrawidya, (Vol. 14, No. 3, 2013), hlm. 442.

Imam Subarkah, Sekilas 125 Tahun Kereta Api Kita 1867-1992, (Bandung: Yayasan Pustaka- PT Intergrafika, 1992), hlm. 9.

Kamus Besar Bahasa Indonesia, Jakarta : Balai Pustaka, 2016

Moleong, Lexy J. 2010. Metodologi Penelitian Kualitatif. Bandung: Remaja Rosdakarya.

Poloma, M. Margaret. 2000. Sosiologi Kontemporer, Jakarta : CV. Rajawali

Pruitt, Dean G dan Jeffrey Z. Rubin. 2009. Teori Konflik Sosial. Pustaka Pelajar: Yogyakarta

Qomarun,Prayitno Budi, Morfologi Kota Solo (tahun 1500-2000), Yogyakarta : Universitas Kristen Petra, 2007), Vol. 35 No 1

Ritzer, George dan Douglas J Goodman. 2008. Teori Sosiologi Modern. Jakarta: Kencana.

Rudolf Mrazek, Engineers of Happy Land Perkembangan Teknologi dan Nasionalisme di Sebuah Koloni, (Jakarta: Yayasan Obor Indonesia, 2006 ), hlm.8.

Silalahi, Ulber. 2009. Metode Penelitian Sosial. Bandung: PT Refika Aditama.

Soekanto, Soerjono. 1992. Memperkenalkan Sosiologi, Jakarta : CV. Rajawali Press

Soekanto, Soerjono. 2006. Sosiologi Suatu Pengantar, Jakarta : Raja Grapindo Persada

Susan, Novri . 2010. Pengantar Sosiologi Konflik dan isu-isu Konflik Kontemporer, Jakarta :

Kencana

Sutopo, HB. 2006. Metodologi Penelitian Kualitatif edisi Kedua. Surakarta: UNS Press

Undang-undang republik Indonesia nomer 7 tahun 2012 Tentang Penanganan Konflik Sosial pasal 1 


\section{Jurnal :}

Amaya Andri Damaini, Ginanjar Setyo Nugroho dan Suyoto. 2018. Fraud Crime Mitigation of Mobile Application Users for Online Transportation.Vol 12 No 3

Ardiansyah, Angga . 2016. Interaksi Komunikasi GoJek (ojek online) dalam Menyelesaiakan Konflik dengan Opang (Ojek Pangkalan). Jakarta : Universitas Mercubuana

Darma, Fania. 2016. Kreativitas Digital Dalam Masyarakat Risiko Perkotaan: Studi Tentang Ojek Online "Go-Jek" di Jakarta. Jakarta : Universitas Indonesia

Demartoto, Argyo. 2017. "Pemahaman Akan Konflik Pada Masyarakat Industri Menurut Lewis Coser dan Ralf Dahrendof" ; 24 (1), 1-48. Universitas Sebelas Maret Surakarta

Perdana, Muhammad. 2018. Faktor Penyebab Konflik Antara Ojek Online Dan Ojek Konvensional (Studi Kasus Ojek Online Dan Konvensional Di Kota Bandar Lampung). Universitas Lampung

Siti Nadhilah, 2017. Fenomena Penggunaan Aplikasi Gojek Di Kalangan Mahasiswa Kota Bandung. Bandung. Universitas Pasundan.

Swastika, Mega . 2017 . Fungsionalitas Konflik Gojek: Studi Fenomenologi Terhadap Konflik Pengemudi Gojek di Kota Kediri. Universitas Sebelas Maret Surakarta.

Yusup,2017.Konflik Sosial Antara Ojek Online Dan Ojek Konvensional (Ojek Pangkalan) Sebagai Akibat Keberadaan Gojek: Studi Deskriptif Di Kecamatan Sukasari, Bandung. Other Thesis, Universitas Pendidikan Indonesia. 